\title{
Genetic variation and relationships of eighteen Chinese indigenous pig breeds
}

\author{
Shu-Lin YANG $^{\mathrm{a}}{ }^{\mathrm{b}}$, Zhi-Gang $\mathrm{WANG}^{\mathrm{b}}$, Bang LiU ${ }^{\mathrm{a}}$, \\ Gui-Xiang ZHANG ${ }^{b}$, Shu-Hong ZHAO ${ }^{\mathrm{a}}$, Mei $\mathrm{YU}^{\mathrm{a}}$, Bin FAN ${ }^{\mathrm{a}}$, \\ Meng-Hua $\mathrm{Li}^{\mathrm{a}}$, Tong-An XIONG ${ }^{\mathrm{a}}$, Kui $\mathrm{Li}^{\mathrm{a}}{ }^{\mathrm{*}}$ \\ ${ }^{a}$ Laboratory of Molecular Biology and Animal Breeding, \\ School of Animal Science and Veterinary Medicine, \\ Huazhong Agricultural University, Wuhan 430070, P.R. China \\ ${ }^{\mathrm{b}}$ Center of Preservation and Utilization of Germplasm Resource \\ of Animal Husbandry and Forage Grass, \\ National Animal Husbandry and Veterinary Service, \\ Ministry of Agriculture, Beijing 100094, P.R. China
}

(Received 14 June 2002; accepted 31 March 2003)

\begin{abstract}
Chinese indigenous pig breeds are recognized as an invaluable component of the world's pig genetic resources and are divided traditionally into six types. Twenty-six microsatellite markers recommended by the FAO (Food and Agriculture Organization) and ISAG (International Society of Animal Genetics) were employed to analyze the genetic diversity of 18 Chinese indigenous pig breeds with 1001 individuals representing five types, and three commercial breeds with 184 individuals. The observed heterozygosity, unbiased expected heterozygosity and the observed and effective number of alleles were used to estimate the genetic variation of each indigenous breed. The unbiased expected heterozygosity ranged between 0.700 (Mashen) and 0.876 (Guanling), which implies that there is an abundant genetic variation stored in Chinese indigenous pig breeds. Breed differentiation was shown by fixation indices $\left(F_{I T}, F_{I S}\right.$, and $\left.F_{S T}\right)$. The $F_{S T}$ per locus varied from 0.019 (S0090) to 0.170 (SW951), and the average $F_{S T}$ of all loci was 0.077 , which means that most of the genetic variation was kept within breeds and only a little of the genetic variation exists between populations. The Neighbor-Joining tree was constructed based on the Nei $D_{A}$ (1978) distances and one large cluster with all local breeds but the Mashen breed, was obtained. Four smaller sub-clusters were also found, which included two to four breeds each. These results, however, did not completely agree with the traditional type of classification. A Neighbor-Joining dendrogram of individuals was established from the distance of $\ln$ (proportions of shared alleles); $92.14 \%$ of the individuals were clustered with their own breeds, which implies that this method is useful for breed demarcation. This extensive research on pig genetic diversity in China indicates that these 18 Chinese indigenous breeds may have one common ancestor, helps us to better understand the relative distinctiveness of pig genetic resources, and will assist in developing a national plan for the conservation and utilization of Chinese indigenous pig breeds.
\end{abstract}

\section{genetic variation / population structure / microsatellite / pig / Chinese indigenous breed}

\footnotetext{
*Corresponding author: 1kxblghi@public.wh.hb.cn
} 


\section{INTRODUCTION}

China is one of the countries possessing the most abundant genetic resources of pig breeds in the world. One hundred and twenty-eight Chinese indigenous pig breeds were documented in the domestic animal diversity information system (DAD-IS) of the Food and Agriculture Organization (FAO), which includes almost one-third of all pig breeds in the world. Many Chinese indigenous pig breeds have their own special characteristics, such as high prolificacy and good meat quality. From the 1970s to 1980s, the achievements of a national project on the investigation and characterization of Chinese indigenous pig breeds organized by the Ministry of Agriculture of China were concluded in the book, Pig Breeds in China [27]. In this book, all of these Chinese indigenous breeds are classified into 48 breeds, which are divided into six types according to their evolutionary origin, geographic distribution, figure, color and product performance. They are the North China Type (I), Lower Changjiang River Basin Type (II), Central China Type (III), South China Type (IV), Southwest Type (V) and Plateau Type (VI). According to the records of this book, Chinese indigenous pig breeds are derived from several kinds of wild boar. The South China wild boar (Sus scrofa chirodontus) and North China wild boar (Sus scrofa moupiensis) are the two main originators [27].

In the last twenty years, many commercial pig breeds have been introduced into China for commercial interests, which have endangered the genetic resources of Chinese indigenous pigs. Both the number and size of Chinese local breeds have decreased dramatically in recent years because their performances, particularly in growth rate, food conversion efficiency and lean meat percent, are much lower than those of the commercial breeds of European and American origins. The assessment of the genetic variation and population structure of Chinese indigenous pig breeds is an essential task for animal genetics studies and government decision-making for breed conservation. The genetic variation of Chinese indigenous pig breeds has been evaluated by cytogenetic and biochemical methods [3,10,22]. Recently, randomly amplified polymorphic DNA (RAPD) [11] and microsatellite markers [17] have also been used. However, all of these studies are only based on a few breeds, and most of these studies are focused on the Central China Type and Lower Changjiang River Basin Type. There are also some reports on the Southwest Type using biochemical methods and mitochondrial DNA [14]. But no previous studies have been conducted on a wide range of Chinese indigenous pig populations as in the present report.

The present research is a part of the national project on the Measurement of Genetic Distance among Chinese Indigenous Breeds organized by the Ministry of Agriculture of China. We analyzed the genetic variation and relationship of 18 Chinese indigenous pig breeds that are distributed all over China. 
Three commercial breeds have been used as outgroups in constructing the dendrogram tree. Initially, Bowcock [1] utilized the simple allele sharing statistics based on microsatellite markers to establish the human evolutionary tree with high resolution, which treats each individual as an operational taxonomic unit. The method was then used to construct the structure of the closely related populations and allocate breeds of sheep, cattle and pigs $[6,18,19]$. In this study, 20 individuals of each breed were chosen randomly from all breeds to establish a dendrogram tree of individual animals.

\section{MATERIALS AND METHODS}

The International Society of Animal Genetics (ISAG) and the FAO recommend a panel of 27 microsatellite loci for the genetic diversity evaluation of global pig breeds. Microsatellites have many characteristics that make them ideal for this purpose.

\subsection{Sampling and DNA isolation}

One thousand and one Chinese indigenous pig individuals and 184 commercial pig individuals were sampled from 18 Chinese indigenous breeds and 3 commercial breeds. Eighteen Chinese indigenous breeds represent 5 of the total 6 types of Chinese indigenous breeds described in the book, Pig Breeds in China [27]. They are the North China Type, Central China Type, South China Type, Southwest Type and Plateau Type. The genetic variation of another type among these 6 types, the Lower Changjiang River Basin Type, has been studied with the same panel of microsatellites in our laboratory [7]. The three commercial breeds are the Large White (LW), Landrace (LD) and Duroc (DR). The 18 indigenous breeds were sampled from the pig breeding farms and villages from nine provinces (Fig. 1). The three commercial breeds were sampled from the pure breeding farms in Beijing. According to the sampling rules recommended by the ISAG-FAO, each studied breed should include more than 50 individuals with a half sire and half dam. For the pressure of market competition, the number of sires is much smaller in the breeding farms, which resulted in the number of sires in this study being much smaller than the dams. Most of our samples, which were collected from indigenous conservation breeding farms, are unrelated (without common grandparents) and have recorded pedigrees. Some samples without completely written pedigree records were randomly collected from the backyards of farmers who are contracted to raise the indigenous pigs by local governments and also receive subsidies from local governments. More details about the types, locations, abbreviations, the number of males and females are given in Table I. Genomic DNA was extracted from blood according to the previous methods of our laboratory [4]. 


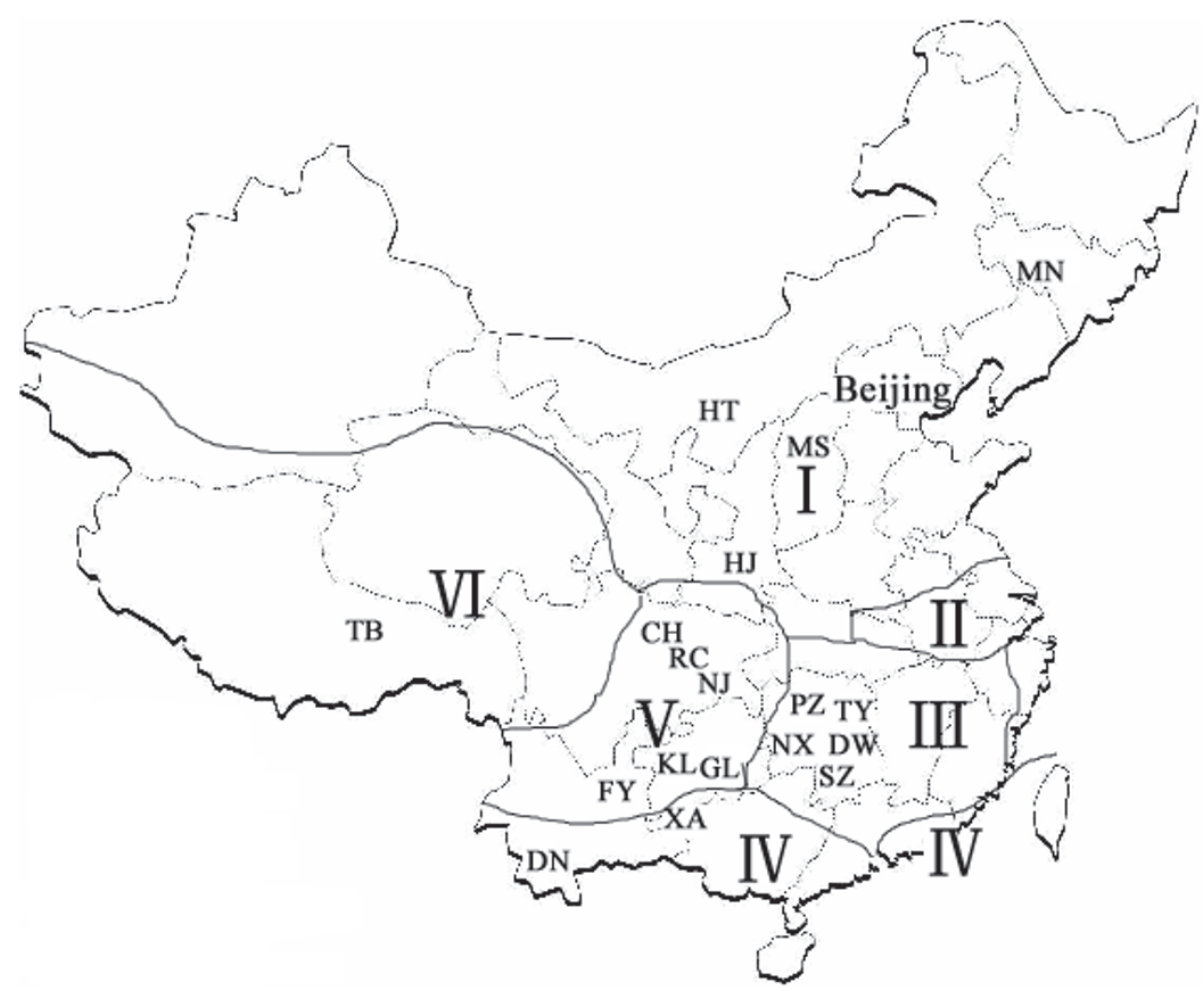

Figure 1. The geographical distribution of 18 Chinese indigenous pig breeds (in a partial map) and the types they belong to. The black line is the boundary of the types. Beijing is the capital of China. Types: I = North China Type; II = Lower Changjiang River Basin Type; III = Central China Type; IV = South China Type; V = Southwest Type; and VI = Plateau Type.

Breeds: $\mathrm{MN}=$ Min; HJ = Hanjiang Black; MS = Mashen $; \mathrm{HT}=$ Hetao LargeEar $; \mathrm{XA}=$ Xiang; DN = Diannan Small-Ear $; \mathrm{TY}=$ Taoyuan $; \mathrm{NX}=$ Ningxiang; $\mathrm{DW}=$ Daweizi $; \mathrm{SZ}=$ Shaziling $; \mathrm{PZ}=$ Penzhou Mountain $; \mathrm{RC}=$ Rongchang; $\mathrm{NJ}=$ Neijiang; $\mathrm{CH}=$ Chenghua $; \mathrm{KL}=$ Kele $; \mathrm{FY}=$ Fuyuandahe $; \mathrm{GL}=$ Guanling; $\mathrm{TB}=$ Tibet .

\subsection{Microsatellite genotyping}

A total of 26 microsatellite markers were chosen from a set of 27 microsatellites recommended by ISAG-FAO. All primers were synthesized in the Sangon Biotechnology Company (Beijing, China). DNA samples were amplified using an Amp9600 Thermal Cycler (PE Company and ABI Company, USA). The PCR conditions were optimized according to the referenced protocols. Three microliters of the denatured PCR products were loaded into an $8 \%$ denaturing polyamide sequencing gel. At the same time, the DNA ladders PBR322 DNA/MspI and PGEM-3zf(+) DNA/HaeIII (SABC Biotechnology 
Table I. Details of sampling information of 18 Chinese indigenous pig breeds and 3 commercial pig breeds.

\begin{tabular}{|c|c|c|c|c|c|c|}
\hline \multirow[t]{2}{*}{ Type } & \multirow[t]{2}{*}{ Province } & \multirow[t]{2}{*}{ Breed name } & \multirow[t]{2}{*}{$\begin{array}{l}\text { Abbre- } \\
\text { viation }\end{array}$} & \multicolumn{3}{|c|}{$\begin{array}{c}\text { The Number of } \\
\text { individual }\end{array}$} \\
\hline & & & & Male & Female & Total \\
\hline \multirow{4}{*}{$\begin{array}{l}\text { North China } \\
\text { Type }\end{array}$} & Heilongjiang & Min & $\mathrm{MN}$ & 4 & 56 & 60 \\
\hline & Shannxi & Hanjiang Black & $\mathrm{HJ}$ & 6 & 54 & 60 \\
\hline & Shanxi & Mashen & MS & 9 & 51 & 60 \\
\hline & Inner Mongolia & Hetao Large-Ear & HT & 8 & 43 & 51 \\
\hline \multirow{2}{*}{$\begin{array}{l}\text { South China } \\
\text { Type }\end{array}$} & Guizhou & Xiang & $\mathrm{XA}$ & 4 & 56 & 60 \\
\hline & Yunnan & Diannan Small-Ear & $\mathrm{DN}$ & 8 & 52 & 60 \\
\hline \multirow{4}{*}{$\begin{array}{l}\text { Central } \\
\text { China Type }\end{array}$} & Hunan & Taoyuan & TY & 17 & 43 & 60 \\
\hline & Hunan & Ningxiang & NX & 7 & 53 & 60 \\
\hline & Hunan & Daweizi & DW & 7 & 49 & 56 \\
\hline & Hunan & Shaziling & $\mathrm{SZ}$ & 6 & 45 & 51 \\
\hline \multirow{7}{*}{$\begin{array}{l}\text { Southwest } \\
\text { Type }\end{array}$} & Hunan & Penzhou Mountain & $\mathrm{PZ}$ & 1 & 56 & 57 \\
\hline & Sichuan & Rongchang & $\mathrm{RC}$ & 3 & 56 & 59 \\
\hline & Sichuan & Neijiang & $\mathrm{NJ}$ & 3 & 57 & 60 \\
\hline & Sichuan & Chenghua & $\mathrm{CH}$ & 4 & 56 & 60 \\
\hline & Guizhou & Kele & KL & 3 & 57 & 60 \\
\hline & Yunnan & Fuyuandahe & FY & 12 & 48 & 60 \\
\hline & Guizhou & Guanling & GL & 5 & 28 & 33 \\
\hline Plateau Type & Tibet & Tibet & TB & - & - & 34 \\
\hline \multirow{3}{*}{$\begin{array}{l}\text { Commercial } \\
\text { breeds }\end{array}$} & & Large White & LW & 12 & 54 & 66 \\
\hline & & Landrace & LD & 8 & 48 & 56 \\
\hline & & Duroc & DR & 11 & 51 & 62 \\
\hline
\end{tabular}

company, China) were loaded into the middle of each panel gel. After $2-3 \mathrm{~h}$ of electrophoresis, the gels were silver stained and were scanned using a Fotodyne gel analyzer (Incorporated Hartland Company, USA). To ensure the accuracy of allele calling, the PCR products of microsatellites of two samples were cloned and sequenced and then used as the control animals in our studies. In the later stage of this research, the control DNA, F9110010 and F9110012, kindly provided by Dr. Denis Milan of Inra, France, were also used to adjust our microsatellite data.

\subsection{Data analysis methods}

The GENEPOP 3.3 [24] computer package was employed in calculating the number of alleles, allele frequencies and fixation indices $\left(F_{I T}, F_{I S}\right.$, and $\left.F_{S T}\right)$. 
The exact Hardy-Weinberg equilibrium test was carried out for each locus in each population based on the alternative hypothesis with heterozygosity deficiency. The length of the Markov chain was set to 1000 iterations per batch for 300 batches and the dememorization number was 1000. The multiple test significance was assayed using the standard Bonferroni correction [9]. The effective number of alleles was computed according to the Kimura and Crow formula [13]. DISPAN [23] was used to estimate the unbiased expected heterozygosity of all loci. The Neighbor-Joining tree of all breeds was constructed from Nei $D_{A}$ (1978) [21] distances using the DISPAN program. $-\ln$ (proportions of shared alleles) distances between individuals [1] calculated by MICROSAT 1.5b [20] were applied to analyze the genetic structure of the individuals. The NJ tree of individuals was constructed by the PHYLIP3.57c [8] software package. The GeneClass program [5] was used to compute the proportion of the individuals correctly assigned to the populations.

\section{RESULTS}

\subsection{Genetic variation within breed}

Allele frequencies are available from the corresponding author upon request. All loci were polymorphic and the total alleles per locus varied from 8 (SW951) to 31 (CGA and SO005) in all populations (Tab. II). The mean value of all loci was 19.34. Four loci (CGA (31), S0002 (30), S0005 (31), S0068 (30)) had more than 25 alleles. Eight markers (S0026, S0178, SW122, SW24, SW632, SW72, SW857, SW936) had one predominant allele in all populations. The number of observed alleles and effective alleles of each population are shown in Table III. The mean number of observed alleles in the single breed was between 10.54 (Mashen, MS) and 14.46 (Daweizi, DW) in the single breed and the average effective alleles ranged from 5.28 (MS) to 8.41 (Kele, KL). The expected heterozygosity of all breeds ranged from 0.700 (MS) to 0.876 (Guanling, GL). Breed differentiation was shown by fixation indices $\left(F_{I T}, F_{I S}\right.$, and $F_{S T}$. The $F_{S T}$ per locus was varied from 0.019 (S0090) to 0.170 (SW951) and the average $F_{S T}$ of all loci was 0.077 , which implied that most of the genetic variation lay within breeds, and only a minority existed among breeds, which was consistent with previous studies of other Chinese indigenous pig breeds $[7,17]$.

\subsection{Population structure of Chinese indigenous pig breeds}

A Neighbor-Joining tree (Fig. 2) of Chinese indigenous pig breeds was constructed from Nei $D_{A}$ (1978) distances (Tab. IV) based on the data of 26 microsatellite loci. Three commercial breeds of LW, LD and DR were used as 
Table II. The genetic variation of 26 microsatellite loci in 18 Chinese indigenous pig breeds, including the number of alleles observed (No.), the range of allele size (Size), Fixation indices $\left(F_{I T}, F_{I S}\right.$ and $\left.F_{S T}\right)$.

\begin{tabular}{|c|c|c|c|c|c|c|}
\hline \multicolumn{7}{|c|}{ Chromosome } \\
\hline Arm & Locus & No. & Size & $F_{I T}$ & $F_{I S}$ & $F_{S T}$ \\
\hline $1 p$ & $C G A$ & 31 & $240-322$ & 0.456 & 0.429 & 0.047 \\
\hline $1 q$ & S0155 & 17 & $148-180$ & 0.522 & 0.481 & 0.078 \\
\hline $2 p$ & SW240 & 15 & $90-118$ & 0.522 & 0.455 & 0.123 \\
\hline $2 q$ & S0226 & 19 & $179-217$ & 0.182 & 0.133 & 0.056 \\
\hline $3 p$ & $S W 72$ & 15 & $90-120$ & 0.461 & 0.387 & 0.122 \\
\hline $3 q$ & SOOO2 & 30 & $184-242$ & 0.388 & 0.335 & 0.079 \\
\hline $4 p$ & SO227 & 20 & 224-266 & 0.445 & 0.425 & 0.035 \\
\hline $5 q$ & S0005 & 31 & $204-264$ & 0.155 & 0.095 & 0.066 \\
\hline $5 q$ & $I G F 1$ & 11 & $191-211$ & 0.325 & 0.278 & 0.064 \\
\hline $6 q$ & SW122 & 16 & $110-140$ & 0.476 & 0.452 & 0.042 \\
\hline $6 q$ & SO228 & 22 & $224-266$ & 0.119 & 0.090 & 0.032 \\
\hline $7 q$ & SW632 & 21 & $143-183$ & 0.026 & -0.050 & 0.073 \\
\hline $8 q$ & SO225 & 17 & $168-200$ & 0.277 & 0.234 & 0.057 \\
\hline $8 q$ & S0178 & 15 & $102-136$ & 0.302 & 0.202 & 0.126 \\
\hline $9 p$ & SW911 & 16 & $149-179$ & 0.225 & 0.145 & 0.094 \\
\hline $10 q$ & SW951 & 8 & $123-137$ & 0.364 & 0.234 & 0.170 \\
\hline $11 q$ & S0386 & 20 & $150-190$ & 0.358 & 0.326 & 0.048 \\
\hline $12 q$ & $S 0090$ & 15 & $239-267$ & 0.472 & 0.462 & 0.019 \\
\hline $13 q$ & 50068 & 30 & $204-262$ & 0.406 & 0.373 & 0.053 \\
\hline $13 q$ & S0215 & 19 & $129-181$ & 0.455 & 0.352 & 0.159 \\
\hline $14 q$ & SW857 & 15 & $140-168$ & 0.311 & 0.260 & 0.069 \\
\hline $15 q$ & S0355 & 23 & $245-289$ & 0.332 & 0.302 & 0.042 \\
\hline $15 q$ & SW936 & 23 & $80-124$ & 0.101 & 0.057 & 0.046 \\
\hline $16 q$ & S0026 & 13 & $96-122$ & 0.407 & 0.333 & 0.111 \\
\hline $17 q$ & SW24 & 21 & 95-137 & 0.412 & 0.341 & 0.108 \\
\hline$X q$ & S0218 & 20 & $166-204$ & 0.073 & -0.0001 & 0.073 \\
\hline Mean & & 19.34 & & 0.330 & 0.274 & 0.077 \\
\hline
\end{tabular}

outgroups. Bootstrap values for Chinese breeds varied from 22 to $97 \%$. The Mashen (MS) breed did not cluster with any indigenous breed, and one big cluster included all other 17 Chinese breeds. Within this cluster, two stable sub-clusters (bootstrap value $>0.7$ ) were present. The first one included three breeds (DW, SZ, and NX) of the Central China Type and one breed (Penzhou 
Table III. Genetic variation in 18 Chinese indigenous pig breeds, including the mean of the observed and unbiased expected heterozygosity, mean of effective and observed alleles of each breed.

\begin{tabular}{lccccc}
\hline Breed & \multicolumn{2}{c}{ Mean heterozygosity } & & \multicolumn{2}{c}{ Mean of alleles } \\
\cline { 2 - 3 } \cline { 5 - 6 } & Expected & Observed & & Effective & Observed \\
\hline Penzhou Mountain & 0.855 & 0.654 & & 8.24 & 14.19 \\
Taoyuan & 0.856 & 0.691 & & 7.38 & 13.42 \\
Ningxiang & 0.845 & 0.680 & & 7.76 & 14.23 \\
Daweizi & 0.868 & 0.668 & & 8.25 & 14.46 \\
Shaziling & 0.848 & 0.559 & & 7.73 & 13.15 \\
Hetao Large-Ear & 0.865 & 0.672 & & 7.77 & 13.38 \\
Rongchang & 0.861 & 0.606 & & 7.63 & 14.15 \\
Neijiang & 0.843 & 0.631 & & 6.96 & 13.31 \\
Chenghua & 0.831 & 0.510 & & 6.65 & 12.77 \\
Kele & 0.858 & 0.556 & & 8.41 & 14.23 \\
Fuyuandahe & 0.855 & 0.589 & & 7.78 & 14.27 \\
Min & 0.828 & 0.464 & & 7.27 & 12.92 \\
Xiang & 0.784 & 0.628 & & 6.30 & 12.54 \\
Diannan Small-Ear & 0.820 & 0.574 & & 6.95 & 13.46 \\
Guanling & 0.876 & 0.630 & & 7.73 & 11.85 \\
Hanjiang Black & 0.863 & 0.702 & & 7.84 & 13.50 \\
Mashen & 0.700 & 0.503 & & 5.28 & 10.54 \\
Tibet & 0.865 & 0.646 & & 8.00 & 13.23 \\
Mean & 0.842 & 0.609 & 7.44 & 13.31 \\
\hline
\end{tabular}

Mountain, PZ) of the Southwest Type. The second one was made up of the Guanling (GL) of the Southwest Type and the Hanjiang Black (HJ) of the North China Type. Finally, two weaker $(0.5<$ bootstrap value $<0.7)$ sub-clusters were also identified, one with the Rongchang (RC) and Neijiang (NJ) breeds and the other one with the Diannan Small Ear (DN) and the Xiang (XA) breeds of the South China Type.

A total of 420 individuals were collected to analyze the individual allocation to each breed. Twenty individuals of each breed were randomly chosen from each breed to establish the dendrogram of the individuals (Fig. 3). The NJ tree was constructed based on the $-\ln$ (proportions of shared alleles) distances, which took each individual as an operational taxonomic unit. The individuals of each breed formed a main branch. Three hundred and eighty-seven individuals out of 420 were clustered with the originated breed. 
Genetic variation in Chinese pigs

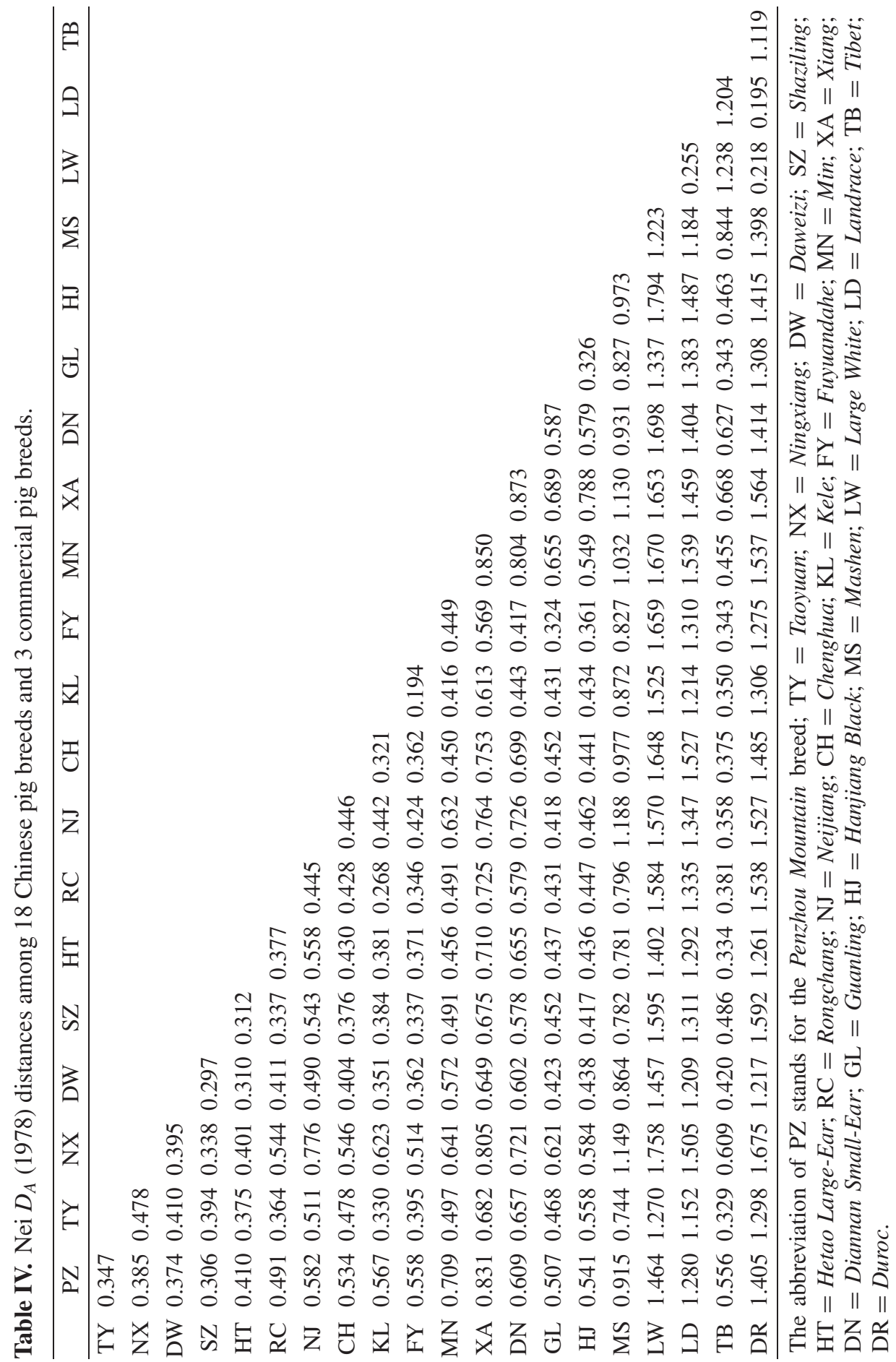




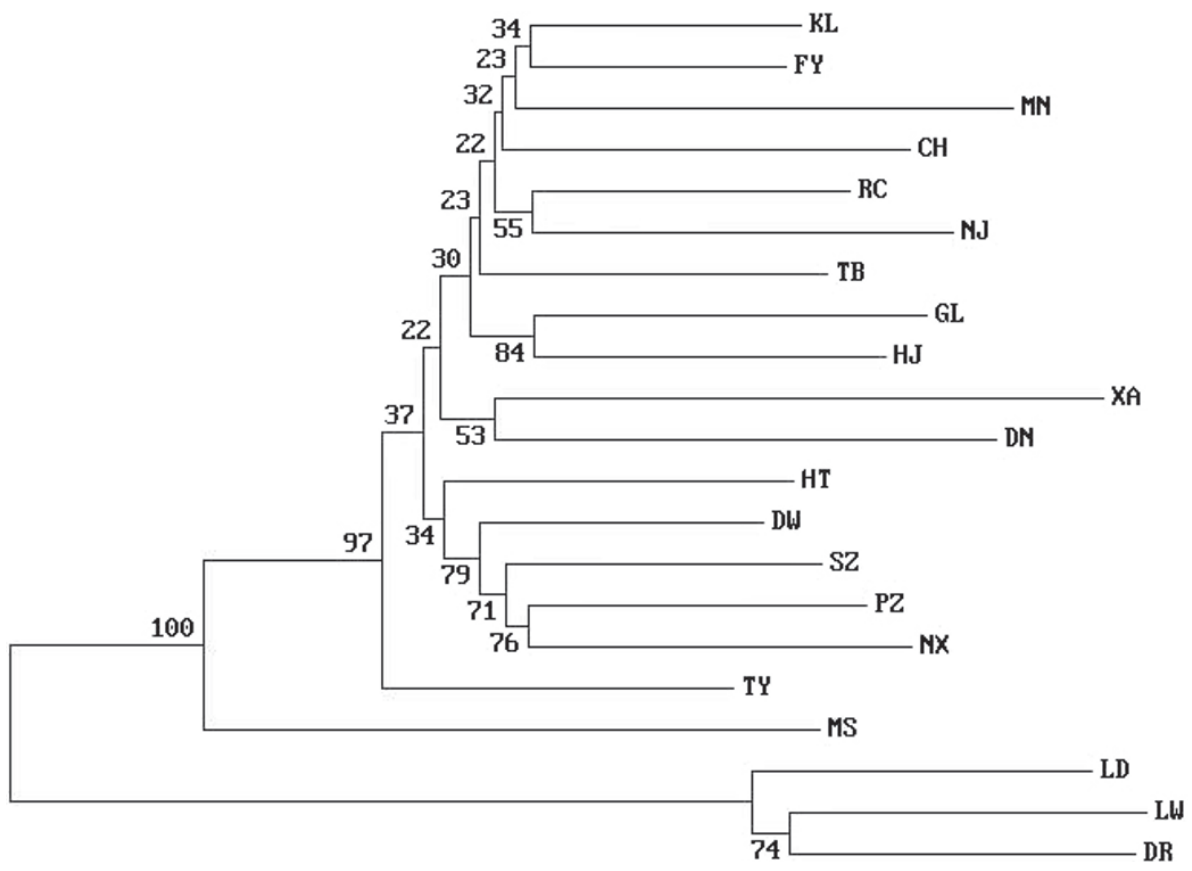

Figure 2. The neighbor-Joining tree of 18 Chinese indigenous pig breeds was constructed from Nei genetic distances $\left(D_{A}\right)$ (1978) based on data of 26 microsatellite markers. The 3 commercial breeds Large White, Landrace and Duroc were used as outgroups. The abbreviation of KL stands for Kele breed; FY = Fuyuandahe; $\mathrm{MN}=$ Min $; \mathrm{CH}=$ Chenghua $; \mathrm{RC}=$ Rongchang $; \mathrm{NJ}=$ Neijiang $; \mathrm{TB}=$ Tibet ; $\mathrm{GL}=$ Guanling $; \mathrm{HJ}=$ Hanjiang Black; XA = Xiang; DN = Diannan Small-Ear; $\mathrm{HT}=$ Hetao Large-Ear $; \mathrm{DW}=$ Daweizi; SZ = Shaziling; PZ = Penzhou Mountain; $\mathrm{NX}=$ Ningxiang $; \mathrm{TY}=$ Taoyuan $; \mathrm{MS}=$ Mashen $; \mathrm{LD}=$ Landrace $; \mathrm{LW}=$ Large White; $\mathrm{DR}=$ Duroc .

\section{DISCUSSION}

\subsection{Genetic variation within breeds}

From the calculation formula $P=1-(1-\alpha)^{1 / k}[9]$, the significant level was calculated to be 0.0024 ( $P$-value) for each of $21(k)$ breeds while $\alpha$ was equal to 0.05 . According to this significant level, every locus deviated from HardyWeinberg equilibrium in at least one Chinese indigenous breed. However, none of the loci was in disequilibria in all of these breeds. The loci deviated from equilibrium ranged from 1 to 6 in each population. In a previous study [7] we showed that the disequilibria were caused by the sample collection. Most of the samples were collected from state-owned conservation farms. So the genetic basis of the pigs was narrow and the founder effect could have an influence on the populations. 


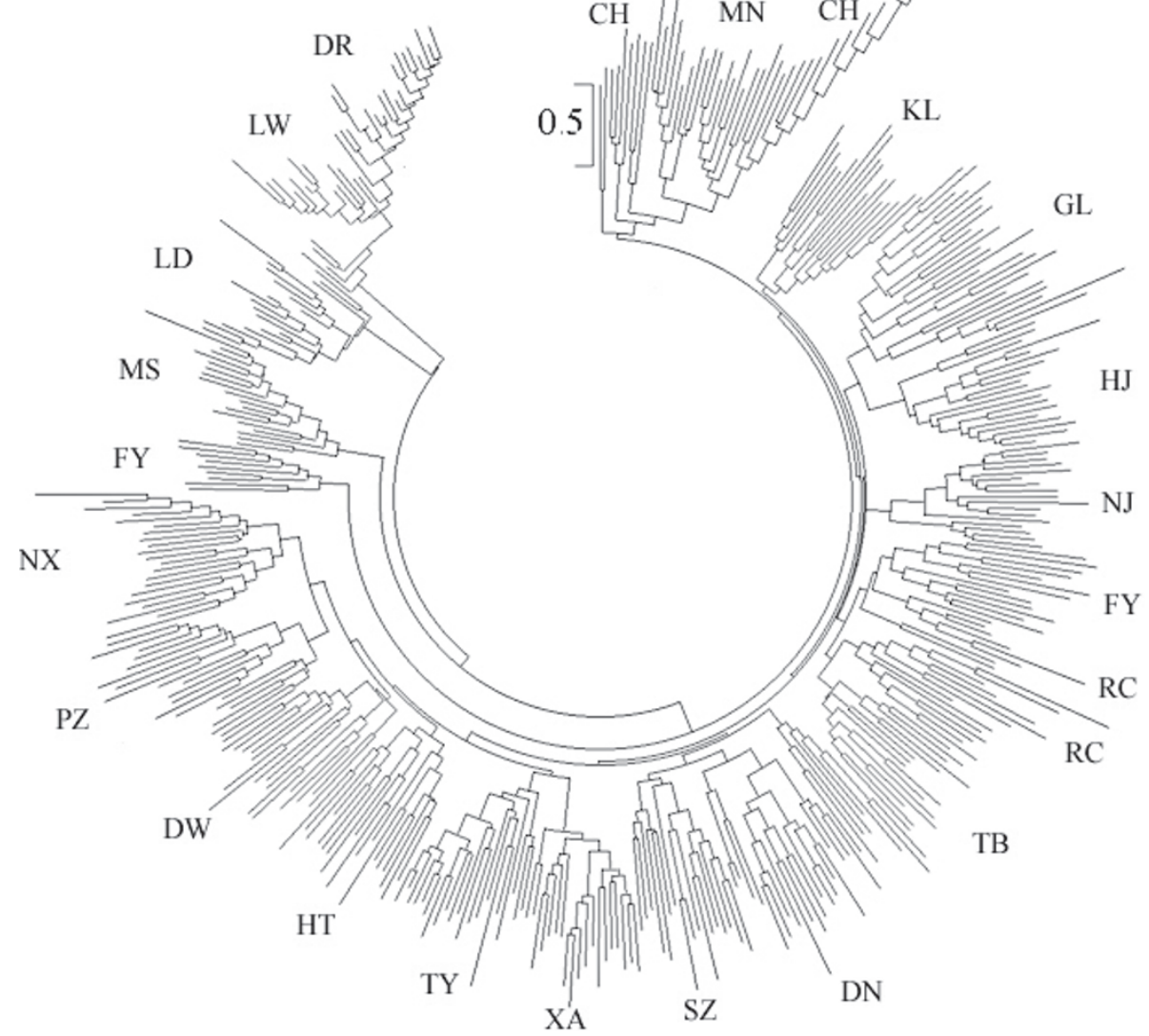

Figure 3. The neighbor-Joining dendrogram was constructed from $-\ln$ (proportion of shared allele) distances among 420 individuals from all breeds. Each individual was treated as an operational taxonomic unit. The abbreviation of $\mathrm{CH}$ stands for Chenghua breed; $\mathrm{MN}=$ Min; $\mathrm{KL}=$ Kele $; \mathrm{GL}=$ Guanling; $\mathrm{HJ}=$ Hanjiang Black; $\mathrm{NJ}=$ Neijiang $; \mathrm{FY}=$ Fuyuandahe $; \mathrm{RC}=$ Rongchang $; \mathrm{TB}=$ Tibet $; \mathrm{DN}=$ Diannan Small-Ear; SZ = Shaziling; XA = Xiang; TY = Taoyuan $; \mathrm{HT}=$ Hetao LargeEar; DW = Daweizi; PZ = Penzhou Mountain $; \mathrm{NX}=$ Ningxiang; MS = Mashen; $\mathrm{LD}=$ Landrace $; \mathrm{LW}=$ Large White $; \mathrm{DR}=$ Duroc .

The number of alleles in each locus across the population ranged from 8 to 31, which was higher than that of the European pig populations and other Chinese pig populations studied $[12,16,17]$. The allele size of all microsatellite loci in these populations was beyond the expected range and that of other Chinese populations studied. Both the mean number of alleles observed and effective alleles were higher than previous studied Chinese breeds. MS had 
the lowest expected heterozygosity, followed by XA, DN, MN, CH, NJ, NX, SZ, PZ, FY, TY, KL, RC, HJ, TB, HT, DW and GL in increasing order. These expected heterozygosity data were generally higher than those of other Chinese indigenous pig breeds $[7,17]$ and the other pig breeds $[12,16,19]$. According to the records of sampling, the 18 breeds studied were distributed throughout an expansive area of China. Most of them were located in the mountainous areas without good transport facilities. There were very few crosses between different indigenous breeds or between indigenous breeds and commercial breeds. Therefore the variation produced in the evolutionary process has been maintained within each breed.

\subsection{Genetic structure of breeds}

Takezaki and Nei [25] compared various measures of genetic distance used for the reconstruction of phylogenetic trees from microsatellite frequency data and showed that the accuracy of the Cavalli-Sforza and Edwards chord distance $\left(D_{C}\right)$ [2] and Nei $D_{A}$ (1978) distance were generally higher than the other distances whether a bottleneck effect existed or not. The accuracy of the dendrogram obtained from such distances, however, is only confirmed for nodes with bootstrap values above 0.70 [15], and the nodes with bootstrap values below 0.50 were not significant. The MS of the North China Type was very much apart from the other indigenous pig breeds. The MS, a fairly isolated breed (Fig. 1), was discovered to be almost extinct in an investigation of Chinese pig breed resources during 1979-1982. The local government collected the remaining pigs of this breed to establish the conservation farm. This breed has the lowest (5.28) mean effective number of alleles, and all loci have one dominating allele. Surprisingly, the well-clustered breeds GL and $\mathrm{HJ}$ belong to two different (but adjacent) regions. On the contrary, all four breeds in the second sub-clusters (DW, SZ, PZ and NX) belonged to the Central China Type. Similarly, the other two indicative nodes united breeds from the same regional types: the Southwest Type for RC and NJ, and the South China Type for DN and XA. Despite records compiled in the book Pig Breeds in China [27], which indicated that all other breeds developed locally without germplasm exchange or crossing, the results of the present cluster analysis indicate that local Chinese breeds generally have a close genetic relationship. Indeed, a recent study showed that a very low level of genetic diversity is present in the near complete mtDNA genome of 17 Chinese indigenous pig breeds representing the 6 types, which also indicates that they may have a common ancestor [26]. Moreover, Lan [14] studied the mitochondrial DNA of pigs in southwest China and also reported that those breeds have a close relationship and a common ancestor. From a phenotypic standpoint, however, the differences between the different types of Chinese indigenous pig breeds in morphology, color and product performance are striking. The XA, for example, 
is a miniature pig, but the body of the MN pig is quite big. The color of the head and rump of the Central China Type is black and its body is white, but many other pig breeds are solid black. Also according to the book, Pig Breeds in China [27], Chinese indigenous pig breeds are derived from several wild boars, which means these breeds have several founders. If the microsatellites used in the present work were not affected directly or indirectly by natural and artificial selection, this study may constitute an accurate report on the genetic variation and the relationships between local Chinese breeds.

\subsection{Genetic structure of individuals}

Thirty-three pigs out of 420 were clustered with different breeds, which means that $92.14 \%$ of the individuals can be assigned into their own breeds. The accuracy of allocating an individual into its own breed with this method was consistent with previous research. In the study of MacHugh et al. [18], 31 individuals did not cluster with animals from the same population in 253 individuals; Martínez et al. [19] showed that the individuals of all breeds clustered together with the expectation of two breeds mixed in the same cluster. At the same time, all individuals were analyzed to determine which breed they would be assigned to with the GeneClass program. Some of the individuals (91.05\%) were assigned to the breeds correctly based on the distance of $-\ln$ (proportion of shared alleles), and $95.27 \%$ based on the distance of the $D_{A}$. So all of the studies showed that this method is useful for breed demarcation. The results of the individual cluster were not completely accordant with that of the breeds. The difference may be caused by the method of distance calculated and only 20 individuals were chosen randomly from the whole breed for individual allocation.

This study showed that there is an abundance of genetic variation stored in Chinese indigenous pig breeds. The genetic distances between these breeds based on the microsatellite markers are quite low. In the NJ tree of these breeds, each branch is constituted with several breeds from more than one type. All of the information may indicate that these Chinese indigenous pig breeds have close relationships and might originate from a common ancestor.

\section{ACKNOWLEDGEMENTS}

This project was supported by the Center of Preservation and Utilization of Germplasm Resource of Animal Husbandry and Forage Grass, National Animal Husbandry and Veterinary Service (NAVS), Ministry of Agriculture, P.R. China, National Nature Science Foundation of China (39970541), Doctorate Foundation of Ministry of Education of China (1999004004), the National Outstanding Youth Science Foundation of China (39925027) and the Key 
Project of National Basic Research and Developmental Plan (G2000016103) of China. This Project also belongs to the EU-China collaboration project (QLRT-2001-01059).

We thank Dr. Denis Milan (Inra, France) for providing the control animal DNA, Jennifer Johnson (Cornell University, USA) for critical reading of the manuscript, Profs. S.J. Guo, G.F. Xu, J.H. Zhang (NAVS, China), H.H. Cao (Chinese Academy of Agricultural Sciences, China) and Y. Zhang (China Agricultural University, China) for their help and useful suggestions. Two anonymous referees are thanked for constructive comments on the paper. Our English teacher Herman Kailola from Australia is also thanked for linguistic revision. Dr. Wendy Brand-Williams, language editor of the Inra journals, and Dr. Francis Minvielle, the scientific editor, are greatly appreciated for their time spent revising the manuscript.

\section{REFERENCES}

[1] Bowcock A.M., Ruiz-Linaraes A., Tomfohrde J., Minch E., Kidd J.R., CavalliSforza L.L., High resolution of human evolutionary trees with polymorphic microsatellites, Nature 368 (1994) 455-457.

[2] Cavalli-Sforza L.L., Menozzi P., Piazza A., The History and Geography of Human Genes, Princeton University Press, Princeton, NJ, 1994.

[3] Chen W., Wang Z., Wang X., Pig Chromosomes of China, Sichuan University Press, Chengdu, P.R. China, 1993.

[4] Chen S.L., Li M.H., Li Y.J., Zhao S.H., Yu C.Z., Yu M., Fan B., Li K., RAPD variation and genetic distance among Tibetan, Inner Mongolia and Liaoning cashmere goats, Asian-Aust. J. Anim. Sci. 14, (2001) 1520-1522.

[5] Cornuet J.M., Piry S., Luikart G., Estoup A., Solignac M., New methods employing multilocus genotypes to select or exclude populations as origins of individuals, Genetics 153 (1999) 1989-2000.

[6] Diez T., Littlejohn R.P., Almeida P.A.R., Genetic variation within the Merino sheep breed: analysis of closely related populations using microsatellites, Anim. Genet. 31 (2000) 243-251.

[7] Fan B., Wang Z.G., Li Y.J., Zhao X.L., Liu B., Zhao S.H., Yu M., Li M.H., Xiong T.A., Li K., Genetic variation analysis within and among Chinese indigenous swine population using microsatellite markers, Anim. Genet. 33 (2002) 222-227.

[8] Felsenstein J., PHYLIP (Phylogeny Inference Package) Version 3.57c, Department of Genetics, University of Washington, Seattle, 1993.

[9] Hochberg Y., A sharper Bonferroni procedure for multiple tests of significance, Biometrika 75 (1988) 800-802.

[10] Hu W.P., Lian L.S., Su B., Nie L., Zhang Y.P., Study on blood protein polymorphism in Yunnan local pig breeds, Heredities (Beijing, P.R. China) 19 (1997) 30-33.

[11] Huang Y.F., Zhang Y.P., Zeng F.T., Study on random amplified polymorphic DNA of four local pig breeds in Sichuan province, J. Sichuan Agric. Univ. (P.R. China) 15 (1997) 95-98. 
[12] Kacirek S.L., Irvin K.M., Dimsoski P.I., Moeller., Davis M.E., Hines H.C., Variation at microsatellite loci in the Large White, Yorkshire and Hampshire breeds of swine, In: Proceeding of the 6th World Congress on Genetics Application to Livestock Production, Armidale, 11-16 January 1998, Vol. 25, University of New England, pp. 640-643.

[13] Kimura M., Crow J.F., The number of alleles that can be maintained in a finite population, Genetics 49 (1964) 725-738.

[14] Lan H., Wang W., Shi L.M., The mitochondrial DNA diversity of pigs in southwest China, Acta Genet. Sinica (P.R. China) 22 (1995) 28-33.

[15] Lanyon S.M., Detecting internal inconsistencies in distance data, System. Zool. 34 (1985) 397-403.

[16] Laval G., Iannuccelli N., Legault C., Milan D., Groenen M.A.M., Giuffra E., Andersson L., Nissen P.H., Jørgensen C.B., Beeckmann P., Geldermann H., Foulley J.L., Chevalet C., Ollivier L., Genetic diversity of eleven European pig breeds, Genet. Sel. Evol. 32 (2000) 187-203.

[17] Li K., Chen Y., Moran C., Fan B., Zhao S.H., Peng Z.Z., Analysis of diversity and genetic relationships between four Chinese indigenous pig breeds and one Australian commercial pig breed, Anim. Genet. 31 (2000) 322-325.

[18] MacHugh D.E., Loftus R.T., Cunningham P., Bradley D.G., Genetic structure of seven European cattle breeds assessed using 20 microsatellite markers, Anim. Genet. 29 (2000) 333-340.

[19] Martínez A.M., Delgado J.V., Rodro A., Vega-Pla J.L., Genetic structure of the Iberian pig breed using microsatellites, Anim. Genet. 31 (2000) 295-301.

[20] Minch E., MICROSAT Version 1.5b (Macintosh), University of Stanford, Stanford, CA, 1998.

[21] Nei M., Estimation of average heterozygosity and genetic distance from a small number of individuals, Genetics 89 (1978) 583-590.

[22] Nie L., Shi L.M., Genetic relationship among several native pig breeds in Southwest China: An approach from blood protein electrophoresis, Chinese Biodiversity 3 (1995) 1-7.

[23] Ota T., DISPAN: Genetic Distance and Phylogenetic Analysis, Pennsylvania State University, University Park, 1993.

[24] Raymond M., Rousset F., GENEPOP (Version 3.3): Population genetics software for exact tests and ecumenicism, J. Hered. 86 (1995) 248-249.

[25] Takezaki N., Nei M., Genetic distance andreconstruction of phylogenetic trees from microsatellite DNA, Genetics 144 (1996) 389-399.

[26] Yang J.E., Wang J., Kijas J., Liu B., Han H., Yu M., Yang H.M., Zhao S.H., Li K., Genetic diversity present within the near complete mtDNA genome of 17 breeds of indigenous Chinese pigs, J. Hered. 94 (2003) 381-385.

[27] Zhang Z.G., The Pig Breeds in China, Shanghai Scientific and Technical Publishers, Shanghai, 1986. 